\title{
HORSE-POWER OF BOILERS.
}

By W. Barnet LeVax, Engineer.

The term "horse-power," in its application to boilers, has hereto. fore been no less indefinite than the same term in its application to the steam engine. It has been customary to fix upon some unit of heating surface as the measure of the horse-power of a steam boiler. The boiler is supposed to furnish a definite amount of steam at the working pressure employed, this amount depending on the heating surface; and the utilization of all this steam, under the most favorable conditions, would thus furnish, through the medium of an engine, a certain amount of work or a certain horse-power. But experiments have shown that the same quantity of water evaporated by a boiler may produce widely different results in the engine, and the work done by the engine dependent upon the evaporation of the water may be changed very materially by the condition of the boiler, as well as by its form and construction. The boiler will do different quantities of work in the same engine, or in different engines under various conditions of working; these conditions being the pressure, the degree of expansion, and the speed of the piston. The horsepower of a boiler will therefore vary with the kind of steam engine, and with its condition.

It is, however, conceded that the amount of water evaporated into dry steam per hour under the ordinary conditions is the best measure of the capacity of the boiler. This amount has been heretofore generally stated at one cubic foot of water evaporated per bour to produce one horse-power.

I propose in this paper to show the horse-power of boilers, as shown by the experiment made at Belmont upon the boilers, engines and pumps of the Water Department, by a commission of gentlemen appointed by the Select and Common Councils of this city, of which Commission $I$ had the lionor of being a member.

BOILERS.

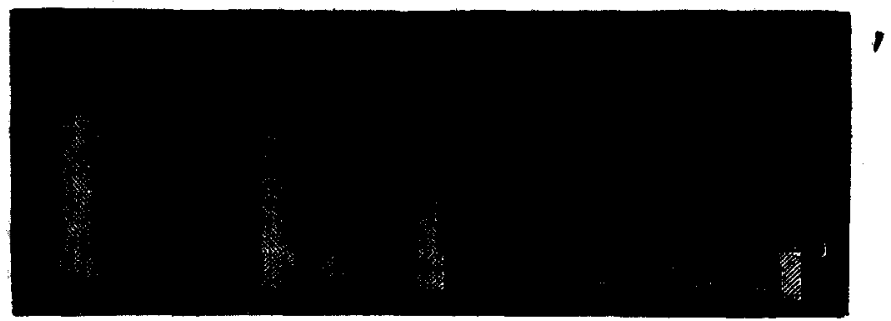


These experiments were made in May, 1872, with six Elephant or French boilers, of the following dimensions :

Total length in feet, . . . . . . $30 \cdot 83$

Diameter in inches, . . . . . . . 54

"Total length of mud drums in feet, . . . $\quad 22$

Diameter of mud drums in inches, . . . . $\quad 28$

Number of mud drums, . $\quad$. $\quad$. $\quad$. $\quad$. 2

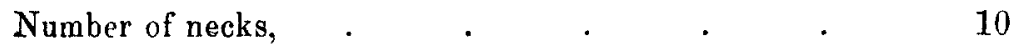

Thength of necks in inches, . . . . . . . $\quad . \quad 12$

$\begin{array}{llll}\text { Diameter of necks in inches, . } & \text {. } & \text {. } & 12\end{array}$

Length of grate bars in inches, . $\quad$. $\quad$. $\quad . \quad 60$

Width of grate-bars in inches, . . . . $\quad 52$

Grate surface of one set in square feet, . . . . $\quad 4333$

Total grate surface of three sets in square feet, . 130

Total heating surface of one set of boilers in square feet, 508

Total heating surface of one set of mud drums in sq. feet, $\quad 616$

Total heating surface of the three sets in square feet, . 3372

Ratio of heating surface to grate surface, $\quad . \quad 26: 1$

\section{DESCRIPTION OF THE DUPLEX PUMPING LNGINE.}

The pumping engines are Worthington's Compound Duplex En. gine, which consist of two high-pressure and two low-pressure cylinders. The initial pressure of the steam is used during the full stroke of the small cylinders, and the low pressure cylinders receive upon their increased piston area the steam discharged from the high-pressure ones. The high and low-pressure cylinders are placed in line, the former being in front of the latter, and the same pistun.rod

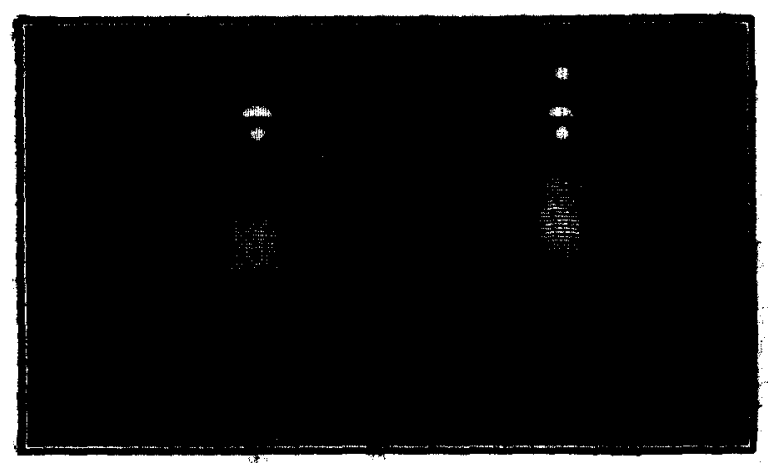

Duplex Pumping Fingine Cylinders. passing through bath, and of such a length as to be attached to the plunger of the purop cylinder situated in advance of the high-pressure cylinder, so as to allow for the guides of the cross. head, and held in this position with the water cylinders in one direst line by four wrought-iron rods, forming : $i n$ oi en space in which are placed two 
single-acting air-pumps for each pair of steam cylinders, which are driven by rock shafts off the main piston-rod, and are in a convenient and acces. sible position beneath the guides. The steam cylinders and heads are steam-jacketed and thoroughly lagged. The steam slide-valves are carefully and simply balanced. The double-acting water-plungers are hollow cylinders with tight heads, their weight being thus nearly floated, and the water entering the numerous suction-valves below them, passes them in a nearly direct line into and through the force-valves above. The valves are rubber disks, backed with iron, working vertically on fixed spindles. The engines, being horizontal, are accessible for inspection and repairs. Each engine drives its plunger at a speed uniform throughout its stroke, during which it opens, by a rock-shaft and appropriate

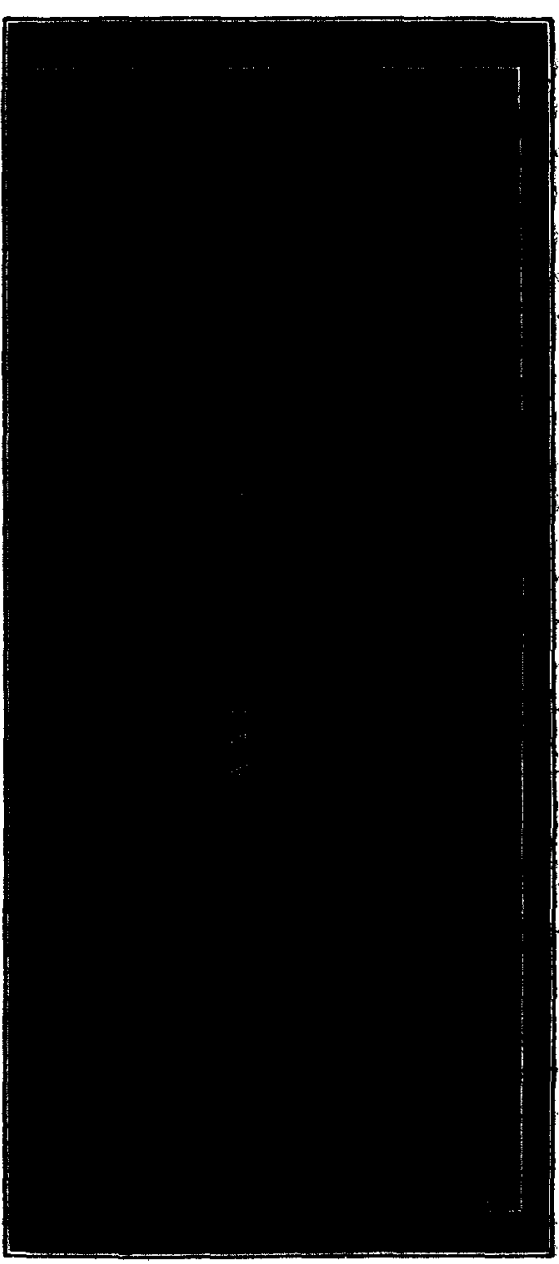

Indicator Diagam. connections, the steam-valve of Taken from the rising main to reservoir. the other, and is obliged to pause at the end of its own stroke until its own steam-valve is opened by the motion of the other piston.

The combined and reciprocal action of the two double-acting plungers is thus driven at unvarying piston speed by the combined pressures in the high and low-pressure steam cylinders (whose sum is a practically uniform quantity), which forces the water in a steady, quiet. stream, as will be seen by the following indicator diagram, taken from the water main leading to reservoir.

The following are the principal dimensions of the cylinders, plungers, etc. : 
DIMENSIONS.

Diameter of high-pressure cylinder in inches, . $\quad 29$

Diameter of low-pressure cylinder in inches, . . $\quad 50.25$

Diameter of water-plungers in inches, . . . 22.50

Diameter of piston-rod in inches, $\quad . \quad$. $\quad . \quad 4$

Travel of pistons between cylinder heads in inches, . $\quad 50$

$\begin{array}{llll}\text { Diameter of air-pumps in inches, } \quad . \quad & 20\end{array}$

Stroke of air-pumps in inches, . . . . . 24

Number of air-pumps, . $\quad . \quad$. $\quad . \quad$. $\quad . \quad 4$

Number of high-pressure steam cylinders, . . . $\quad$. 2

Number of low-pressure steam cylinders, . . . $\quad 2$

$\mathrm{N}$ umber of water cylinders, $\quad$. $\quad . \quad$. $\quad 2$

Number of inlet-valves in one cylinder, $\quad . \quad . \quad 16$

Area of the 16 inlet-valves in square inches, . . 300

Number of outlet-valves in one cylinder, . . . $\quad 16$

Area of the $\mathbf{1 6}$ outlet valves in square inches, . $\quad 300$

THE WORK TO BE PERFORMED BY THE BOILERS.

The water in Fairmount dam to be lifted into the reservoir on George's Hill, situated in Fairmount Park.

The following are the height, length and diameter of main, ramely:

Height to top of overflow pipe in feet, . . $\quad 208$

Length of pumping main in feet, . . . . 4167

Diameter of pumping main in inches, . $\quad . \quad$. 30

MANNER OF CONDUCTIYG THE EXPERIMENT, AND EXPERIMENTAL DATA AND RESULTS.

Previous to the test the pressure-gages were carefully compared with standard test-gages, and a certified statement of their variations sbtained.

The coal scales were tested and sealed by the official sealer of weights and measures.

The evaporation was determined by measuring the water in an open tank previously to its being pumped into the boilers, its capacity being 20 cubic feet; 19 cubic feet was the usual charge at intervals of about ten minutes. A float and gage-rod was provided and marked in cubic feet by actual measurement from a box exactly 12 inches square, and filled 12 inches deep. The correctness of the manner of measurement was verified at the commencement of the trial. As often as emptied, it was refilled through a pipe from the hot-well of the engine. From the tank, the water was forced into the boilers by a 
small steam pump. The measurement of feed water was constantly in charge of an assistant, and every separate charge of water to the boilers was entered into a book kept for the purpose.

The total amount of water supplied to the boilers was 5212 cubic feet. A leak discovered at the commencement in the feed-pipe, which was carefully measured for a given length of time, and thereby the quantity lost was accurately arrived at, amounted to 40 cubic feet (temperature $139^{\circ} \mathrm{Fahr}$, weight 61.52 pounds per cubic foot), reduced the amount of water evaporated to 5172 cubic feet, or 318,181 pounds.

The coal consumed was excellent anthracite, a first quality of steam coal, giving the very small residuum of about 10 per centum.

The coal and ashes were carefully weighed, one or more assistants. being on duty in the fire-room during the whole test, and having a constant supervision thereof.

During the test the pressure of the steam per gage and temperatureof feed water, which for this purpose was drawn from a cock in the pipe a few feet before entering boiler, were taken every twenty minutes. These observations were made by not less than three persons. at the same time, and their notes carefully compared and verified as: the test progressed.

The experiment was commenced at precisely $4.40 \mathrm{P}$. M., on Wednesday, May 15th, and continued until Friday, May 17 th, at 5 o'clock P. M., being of forty-eight hours and twenty minutes duration. At the commencement a large clean fire was upon the grates; the steam pressure in the boiler was 48 pounds per square inch above the atmosphere by an American Steam Gage Company's gage; and the height of the water in the boiler was carefully noted on glass gages: attached to the front head of each boiler, with tubes extending through the brickwork. At the close of the experiment the steam was left at the same pressure in the boilers, and the fires in the same state, as nearly as could be estimated, as at the commencement. The water in the glass gages at the close of the test was 0.17 inch lower than at commencement. The boilers are therefore charged with coal sufficient to bring the deficiency of water (530 pounds) from $129^{\circ} .59$, the temperature of feed-water, to temperature of steam, at 48 pounds. pressure, $295^{\circ}$ Fahr., or 10 pounds of coal.

The following are the experimental data and results: Duration of trial in hours,

Mean temperature of feed water in the tank, in degrees Fahr., 
Mean pressure of the steam in the boiler in pounds, per square inch, above the atmosphere, . . .

Total weight of water evaporated from a temperature of $129^{\circ} .59$ in pounds,

Equivalent weight of water evaporated from and at $212^{\circ}$ Fahr., and atmospheric pressure, 352,676

Total weight of anthracite coal consumed in pounds,

Total weight of ashes, clinker and fine coal withdrawn from ash-pit in pounds,

Per centum of așhes, clinker and fine coal,

Pounds of coal consumed per hour per sq. foot of grate surface,

Pounds of combustible consumed per hour per square foot of grate surface, .

Pounds of water evaporated from a temperature of $129^{\circ} .59$

Fabr., by one pound of coal, .

Pounds of water evaporated from a temperature of $212^{\circ}$

Fahr. by one pound of coal,

Pounds of water evaporated from a temperature of $129^{\circ} .59$

Fahr. by one pound of combustible, . . .

Pounds of water evaporated from a temperature of $212^{\circ}$

Fahr. by one pound of combustible,

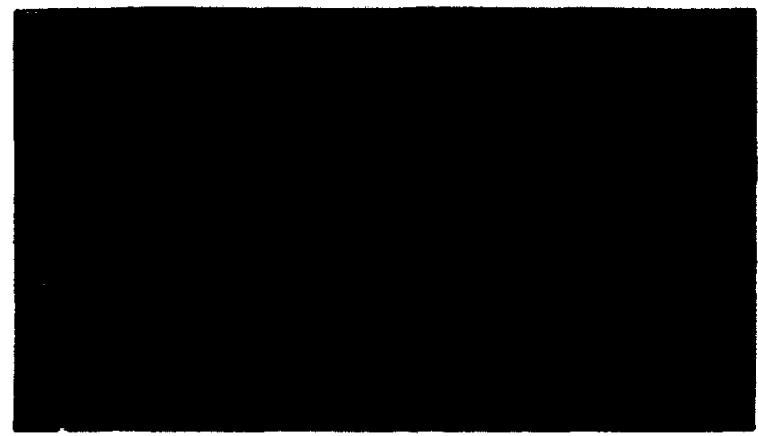

THE WEIR AT RESERVOIR.

The quantity of water discharged at the reservoir was measured over a weir, situated about 24 feet from the overflow of the delivery pipe in the flume, the crest of which was 8 inches lower than the mouth of said pipe, and the water flowing over it at an average depth of 9.2 inches. The sheet of water issuing from the pipe prior to the erection of the weir was about 4 inches deep. Considering all these conditions, the location of the weir was such that it did not obstruct 
the flow of water from the pipe, neither was there such a fall from the pipe to the weir as to occasion any undue velocity in the flume. The flume was 7 feet wide; length of weir, 4 feet. The crest of weir was 5 feet above the bottom of flume, which sloped upwards from the weir towards the delivery-pipe.

To correct any inequalities in the velocity of the water approaching the weir, there were placed in the flume two fine gratings, $G$, about ten feet apart, equi-distant between the pipe and the weir, through which the water flowed before it reached the latter, and by this means an even, regular flow was obtained.

The depth of the water flowing over the weir was ascertained by a hook-gage, graduated to read to the one-thousandth of a foot, located about three feet up stream from the weir, supported by heavy timbers bolted to the masonry to avoid any danger of the gage moving out of its place after it was adjusted. The water in which the hook. gage was inserted was contained in a box communicating by pipes with the centre of a perforated pipe on the up-strcam side of the weir extending nearly across the flume, in this way insuring the level of the water in the hook gage box to be the same that would be due to the pressure of the water across the whole width of the weir.

The velocity of the water in the flume as it approached the weir was 27 of a foot per second. Mr. Francis's correction for this relocity would have added .001 of a foot to the observed depth on the weir. The hook-gage when it recorded zero was accurately adjusted to be level with the crest of the weir at the commencement of the observations, by means of a graduated rule for that purpose.

The observations are recorded as running through 10 minutes, during which time two observations were made, and the average of these two was the depth recorded. The temperature of the water was noted at intervals, and in estimating the number of pounds of water pumped, the number of curic feet of each recorded, temperature was computed.

\section{THE WORK PERFORMED.}

By the above observations there was delivered into the reservoir, namely :

1. In twenty-four hours, in cubic feet,

2.4 " " " " "

3. In twenty minutes " "

$747,047 \cdot 4.5$

$743,622 \cdot 01$

Total,

$9,915 \cdot 06$

$1,500,584 \cdot 52$

The same converted into pounds, at the average temperatures noted amounted to 
1. Twenty-four hours, in pounds,

2.

3. Twenty minutes,

Total in forty-eight hours and twenty minutes,
$46,539,325$

$46,328,629$

617,559

$93,485,51 \%$

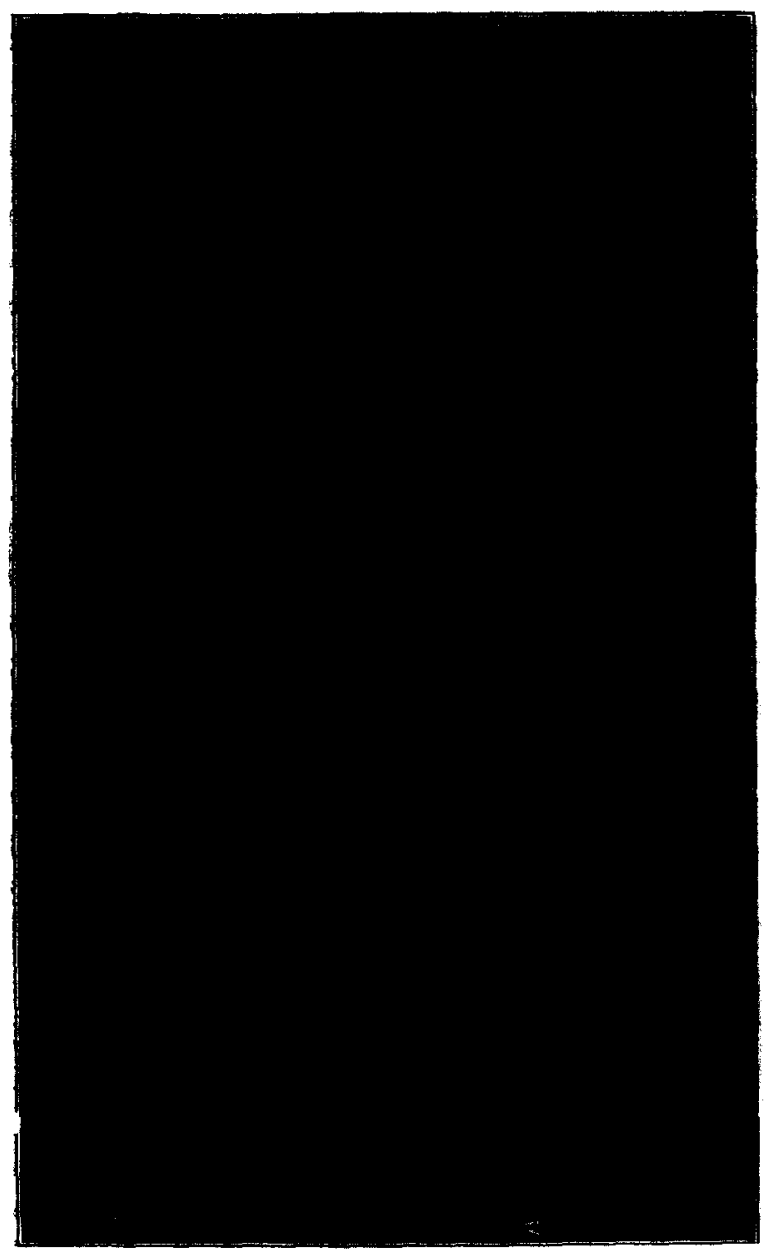

Indicator Dingrams. From the Worthington Duplex Pumping Eugine taken during the experiments at Belmont. scale lif punds to one inch.

RECAPITULATION.

Jotal weight of water evalporated, in pounds, in forty-eight hours and twenty minutes

'otal weight of water evaporated, in pounds, in one hour, 
tively, of enormous power. 1st. Locomotives for industrial, forest and mountain railroads of from 0.632 meters, equal 24 Vienna inches gauge. Two pair of coupled wheels of 0.800 meter diameter, the rear pair of which is on the driving axle, with a wheel-base of 1.500 meters, are below the boiler in front of the fire-box. Both drivers can be braked in front. The brake-spindle is placed at the railing around the footboard. The cranks and bearings of the wheels are after Hall's system, the manner in which the weight is distributed and in which the springs are applied is especially favorable. The two outside cylinders, which are $1.432 \mathrm{~m}$. apart between centres, have a diameter of $0.240 \mathrm{~m}$.; the stroke of the piston is $0.425 \mathrm{~m}$. The boiler, with a diameter of $0.800 \mathrm{~m}$, contains 88 tubes, of a length of $2.540 \mathrm{~m}$., with an outside diameter of $0.046 \mathrm{~m}$. The total heating surface is 34.375 square $\mathrm{m}$.; that of the fire-box 2.792 square m.; that of the grate 0.545 square $\mathrm{m}$. The ratio between the direct and the total heating surface is consequently as $1: 12 \cdot 3$; the ratio between the grate and the heating surface is as $1: 63$, an extraordinarily favorable one, which presupposes the great power of the machine and very great economy in the consumption of fuel. Moreover, the total weight is subservient to adhesion. The copper fire-box roof is staybolted to the iron one, after L. Becker's system, which lessens the overhanging weight of the fire-box, which is $0.810 \mathrm{~m}$. long (the front of which is $0.440 \mathrm{~m}$. distant from the centre of the driver), and avoids too great an elevation of the fire-box, thus favoring a better lookout.

The cubic contents of the water-tank is 1.5 cubic $m$,, and that of the coal bunker 0.75 cubic $\mathrm{m}$. The water tanks are partly at the side of the barrel of the boiler and partly under it, between and above the axles in the form of a cross. The sand-boxes are on both sides of the frame. A dome of a diameter of $0.500 \mathrm{~m}$. is placed near the front of the barrel of the boiler, which is riveted together in only two sections, and contains a safety valve and the regulator. The rear safety-valve, the whistle, the injector-cock and the pressure gauge are placed upon a small cast iron dome, with a diameter of $0.210 \mathrm{~m}$., whose whole arrangement must be pronounced as very ingenious. Blast-pipe, blow-off cock, the manhole and watergauge are arranged in the usual manner. The stack is conical, with Klein's spark arrester.

Stephenson's link motion is placed outside. The eccentrics are fitted on return cranks of the driving axle; the steam chests are 


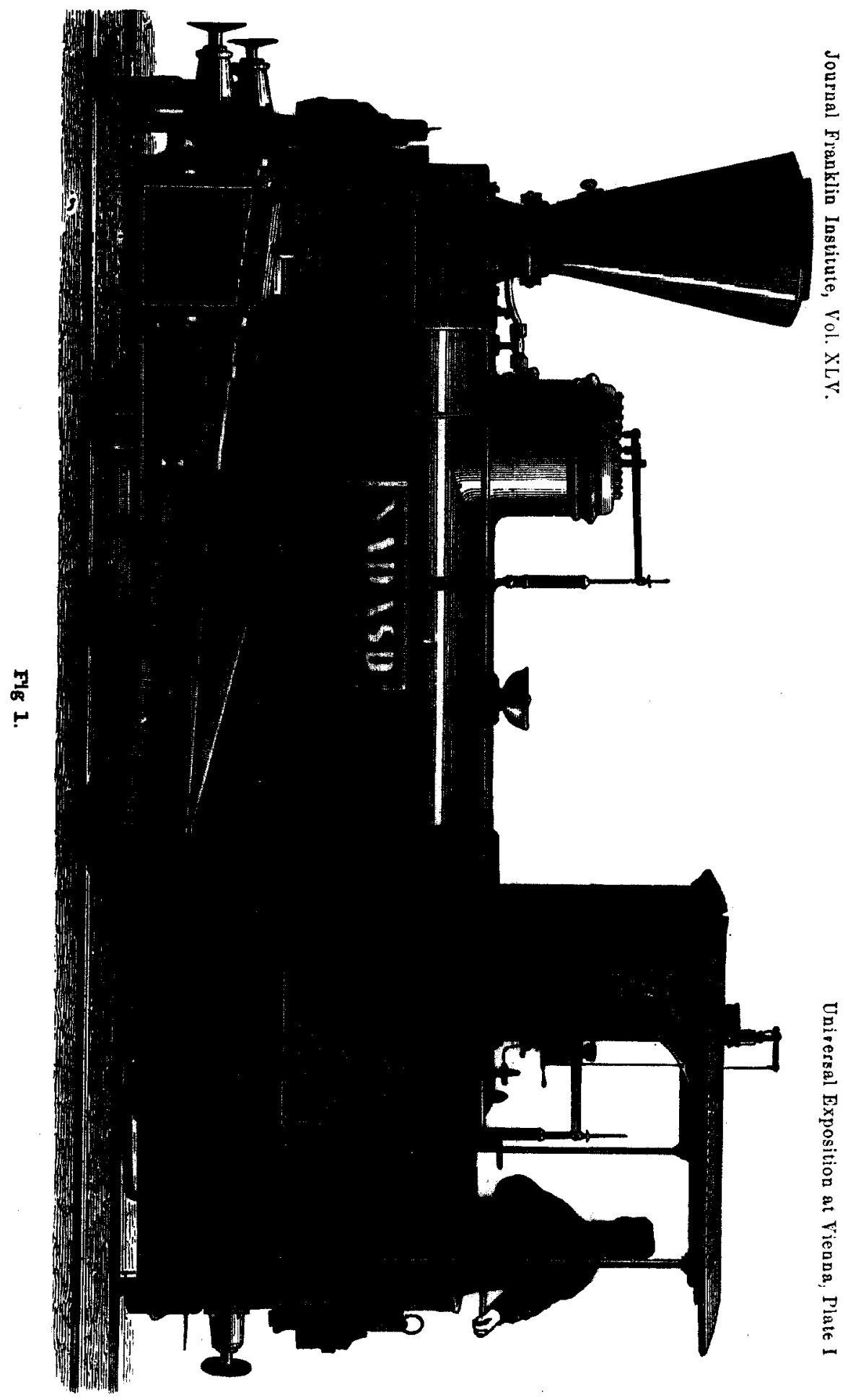


placed obliquely upon the steam-cylinders; the length of the eccentric rods and of the connecting rod is considerable and very favorable. The valve stem is guided in the slot link by a guide fastened to the bracket of the crosshead guides and by the two stuffing boxes of the steam chest.

Drawing hooks, buffers and railguards are symmetrically placed at both ends on iron cross plates. The foot board behind the fire-box is $1.800 \mathrm{~m}$. wide and $0.750 \mathrm{~m}$. long. The former $(1.800 \mathrm{~m}$.) is also the measure of the greatest width of the machine, whose length is $5.630 \mathrm{~m}$. The distance from the front axle to the buffer-end is $1 \cdot 700$ $\mathrm{m}$., from the driving axle to the rear buffer-end $2 \cdot 340 \mathrm{~m}$. The greatest height of the stack above the rails, $2.800 \mathrm{~m}$., and that of the top of the boiler, $1.600 \mathrm{~m}$. The usual cab rises from the footboard. The feeding of the boiler is accomplished by means of two of Friedmann's injectors symmetrically applied. The weight of this machine when in service is 10 tons.

2d. Three-Driver Locomotive for a gauge of $0.750 \mathrm{~m}$. This locomotive has three pair of coupled wheels, whose rear one is the driv. ing wheel. The general arrangement is exactly the same as that of the one previously described.

Greatest length of machine, . . . $\quad$. $5.930 \mathrm{~m}$.

Wheel base, . . . . . $\quad 1.800 \mathrm{~m}$.

From after end of engine to centre of driving wheel, . $2 \cdot 340 \mathrm{~m}$.

From front end to centre of front axle, . . $1 \cdot 790 \mathrm{~m}$.

Distance of axles, . . . . . $\quad . \quad 0.900 \mathrm{~m}$.

Diameter of cylinder, . . . . $0.290 \mathrm{~m}$.

Stroke of piston, . . . . . . $0.425 \mathrm{~m}$.

Diameter of wheels, . . . . $\quad 0.800 \mathrm{~m}$.

Total heating surface, . . . . $38 \cdot 380 \mathrm{s.m}$.

Direct " " . . . . . $3.070 \mathrm{s.m}$.

Grate surface, . . . . . . 0.639 s. m.

Grate surface to heating surface, . . $\quad 1: 60$

Direct heating surface to total heating surface, . $1: 12 \cdot 4$

88 tubes $2 \cdot 840 \mathrm{~m}$. long, with an outside diameter of $0 \cdot 045$.

Distance between centres of cylinders, . $\quad$. $1.550 \mathrm{~m}$.

Width between frames, . . . . $\quad .050 \mathrm{~m}$.

The wanter-tanks hold . . . . 1.75 c. m.

Fuel space, . . . . . 0.85 c. m. 
Weight of engine when empty,

12 tons.

Weight when in service (at the same time weight of adhesion),

15 tons.

Pressure of steam,

10 atmospheres.

3d. Locomotive with 8 coupled wheels for a gauge of $0.750 \mathrm{~m}$. Has four pair of coupled wheels, the last but one being the drivers.

Greatest length of engine, . . . . $6.435 \mathrm{~m}$.

From end to rear axle, . . . . . $2.340 \mathrm{~m}$.

Distance between centres of adjoining axles, . $\quad .0 .760 \mathrm{~m}$.

Total wheel base, . . . . . $2.280 \mathrm{~m}$.

From front axle to end, . . . . $\quad .815 \mathrm{~m}$.

Diameter of cylinder, . . . . $\quad .320 \mathrm{~m}$.

Stroke of piston, . . . . . . $0.425 \mathrm{~m}$.

Diameter of wheels, . . . . $\quad . \quad 0.760 \mathrm{~m}$.

104 tubes $3.300 \mathrm{~m}$. long, of an outside diameter of $\quad 0.045 \mathrm{~m}$.

Total heating surface, . . . . $52.25 \mathrm{s.m}$.

Surface of fire-box, . . . . . . 3.75 s. m.

Grate surface, . . . . . $\quad$. $\quad 0.888$ s. m.

Ratio of grate surface to heating surface, . . . $1: 59$

" "direct to total " " . . . $1: 14$

Steam pressure, . . . . 10 atmospheres.

Water-tanks, . . . . . 2.25 c. m.

Weight of empty engine, . . . 17 tons.

$\because \quad$ in service (weight of adhesion), . . 22 tons.

The last two kinds of engines have the brake invented by Mannbart. The brake-blocks are placed above, between the wheels, on a shoe guided by the boiler supports. They are worked by a lever, connected with them by a link. The spindle lies horizontally; the effect is almost instantaneous, since the brake-blocks, when pulled, press the middle wheels not only to the boxes, but also to the rails. The outer wheels are pressed only to the boxes; a possibility of running off the track is thereby aroided.

There is no doubt that these engines can be furnished at less expense by omitting Hall's system. To be sure some water room is lost by the greater narrowness of the frames, and the motion loses some of its ease; but since the water room is still sufficient for short distances, and since no greater rates of speed are wanted, the transferring of the frames within the wheels might recommend itself. Such machines are at present built in the factory of the Forest \& 
slountain Industrial Company, at Moedling, near Vienna, and have already before been built in the machine works of G. Sigl, in Vienna.

The following table shows the capability of these locomotives in hundred weights ( $=50 \mathrm{kilog})$.

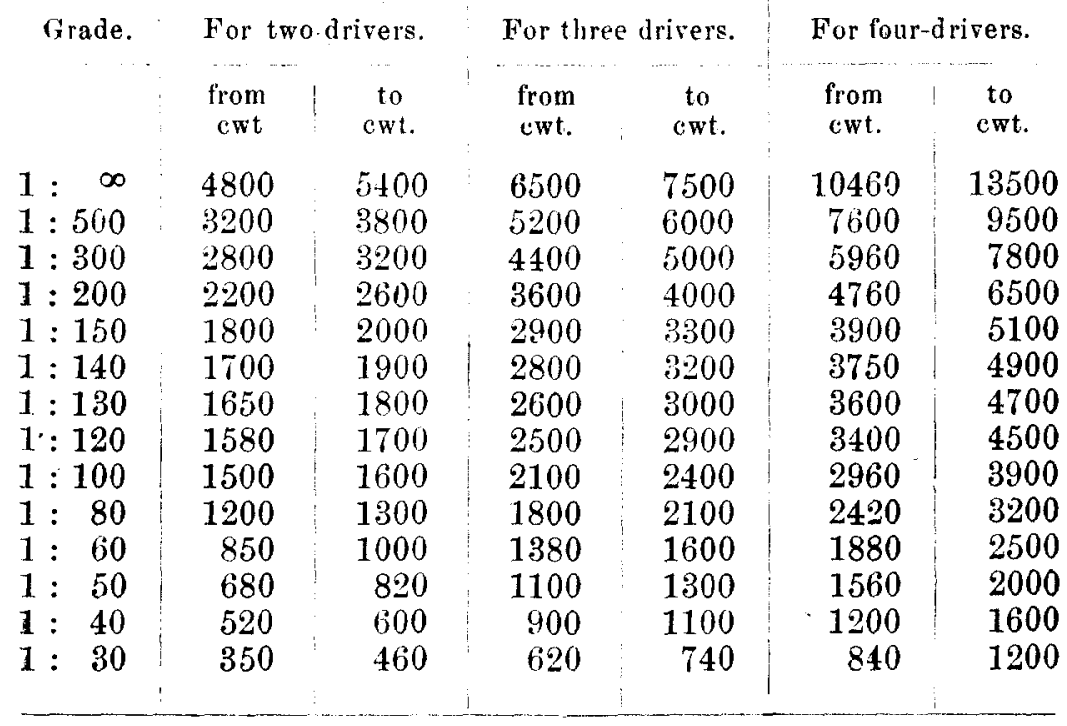

For railroad construction the factory of G. Sigl, in Vienna, has likewise built a very convenient locomotive, which is at the same time provided with a contrivance that allows it to be transported on ordinary roads. This locomotive (represented in Figs. 2 and 3) has received the name of portable locomotive. It is a four-wheeled tank engine, of normal gauge, has a short wheel base, in order to be available for sharp curves, and buffers, the height of which, from the rails, can be changed. At both sides of the boiler water-tanks are attached; both pair of wheels are coupled, and the brake is between the wheels. Fig. 2 shows the locomotive ready for service. For transportation on ordinary roads the front wheels are bound with cast iron tires, the construction and fastening of which may be inferred from Figs. 4, 5 and 6 . Under the platform a carriage with an ordinary wagon-pole is fastened, while the rear wheels of the locomotive are raised from the ground. 
Fig. 2.

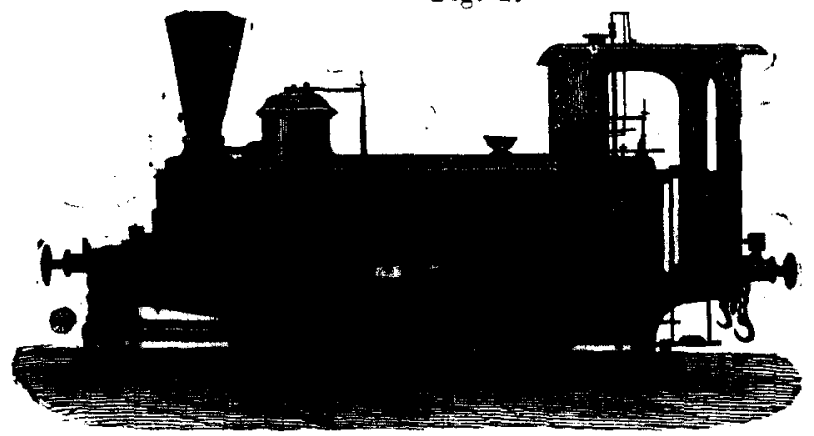

Fig. 3.

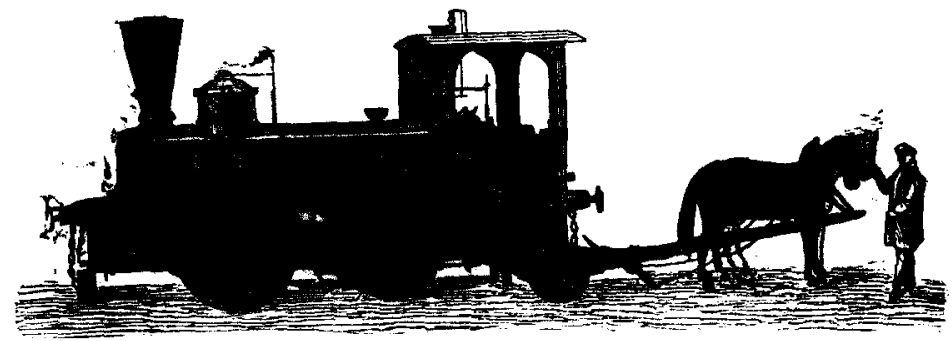

lig. 6.

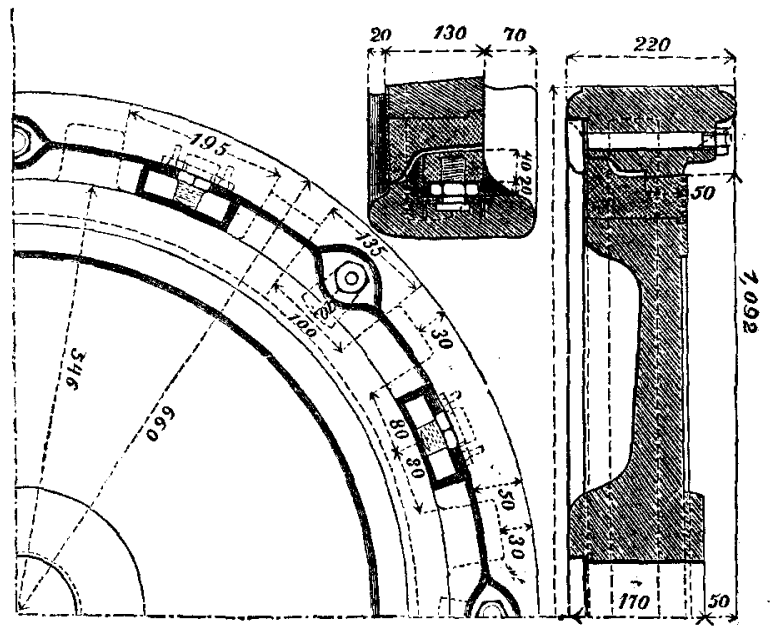

Fig. 4.

Fig. 5 .

This locomotive, as well as the apparatus for transportation, have been found very serviceable, and they are in constant demand. Its. main proportions are as follows: 
Weight of machine in service,

- 18 tons.

" " " when empty,

15 tons.

Diameter of driving wheel,

$1 \cdot 100 \mathrm{~m}$.

Total heating surface (with 84 tubes),

38.867 s. m.

Heating surface of fire-box,

Grate surface,

Diameter of cylinder,

Stroke of piston,

$3 \cdot 242$ s. m.

$0.523 \mathrm{s.} \mathrm{m}$.

$0.265 \mathrm{~m}$.

$0.500 \mathrm{~m}$.

Performance on $\frac{1}{a}$ with $2 \frac{1}{2}$ (German) miles per hour,

exclusive of machine,

$6500 \mathrm{cwt}$.

The same firm have made a blowing engine for blast furnaces, of which I subjoin a photographical representation, and which is distinguished by many interesting details of construction. Two such engines were made for the Schwechat Iron Works. Each machine furnishes the blast for a furnace that melts $1200 \mathrm{cwts}$. of iron per day. The engine is of the compound condensing type, and has a poppet valve motion. The small steam cylinder has a diameter of $33^{\prime \prime}$ and a stroke of piston of $6^{\prime} 10_{4}^{3 \prime \prime}$; the large steam cylinder 100" diameter and stroke of $9^{\prime}$ (all in Vienna measurement). The valves for the blowing cylinder have a circular arrangement. The throttle-valve for the regulation of the blast is new and interesting. It consists of two cones inserted into a globe-shaped chamber of the conducting pipe, which are, by means of a screw spindle, that has a right and left hand thread, removed from one another when the blast is to be shut off, and to be brought near each other when the blast is put on.

A street locomotive by the same firm is also very ingeniously constructed, but somewhat too heavy for ordinary streets. This locomotive has two separate engines, each of which drives a wheel.

I have to mention as another novelty a governor, invented by $\mathrm{Dr}$. R. Proell, Engineer, which is specially distinguished by its simplicity. Whether it possesses the advantages that have been claimed for it and theoretically proved, must be demonstrated by experience derived from its practical application. At all events its pleasing form and convenient arrangement would recommend it even if it should not possess all the eminent advantages claimed for it by the inventor. The following description will enable experts to judge for themselves.

As the wood-cuts in Figs. 1 and 2 show, Dr. Proell's governor is to be considered as an improvement on Porter's governor. The ball Vul. I.XY.Third Series.-No. 6.-J Jiri, 1873. 
Fig. 1.

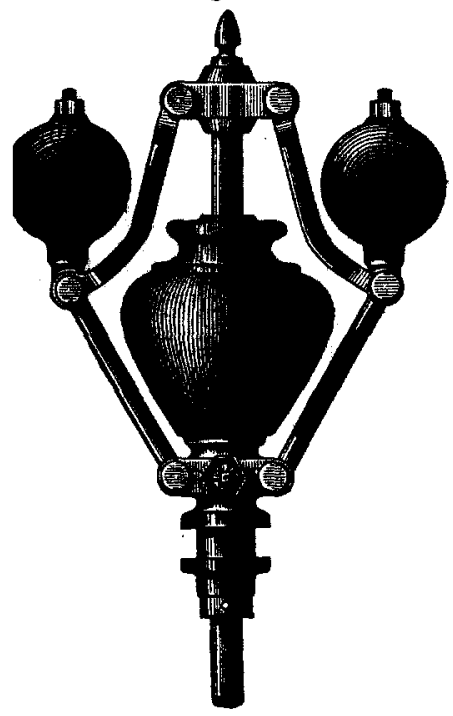

Fig. 2:

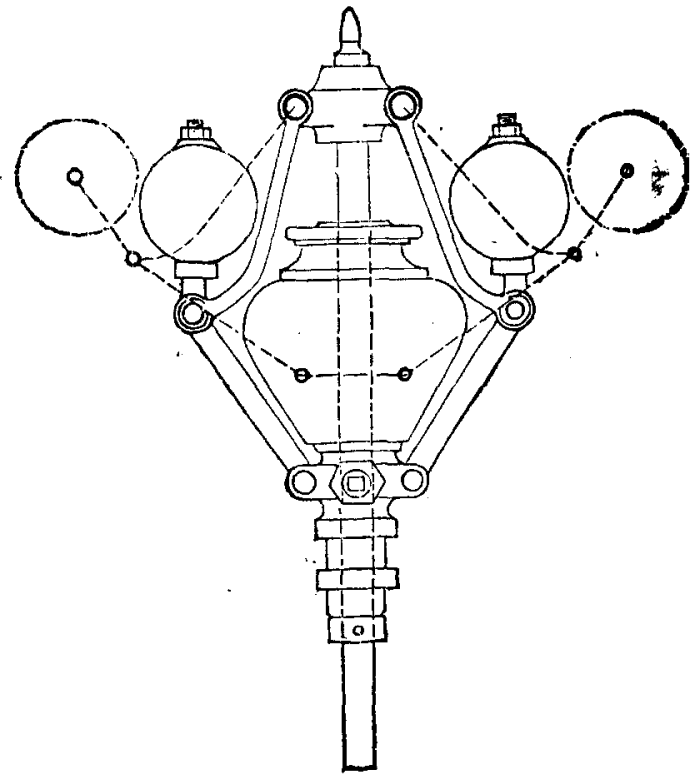

is taken from the joint and placed upon a separate arm, which forms a definite angle with the lower connecting link. The angle BDE is a stationary knee-shaped piece, which, in the upper position of the governor in Fig. 4, occupies the position indicated by the dotted lines. By this change in the position of the balls, Porter's governor, in which the balls swing in a circle around the stationary points at $\mathrm{C}$, has been made pseudo-astatic, i.e. the sleeve accomplishes its way, which lies between the extremes of $50 \mathrm{~mm}$. and $75 \mathrm{~mm}$., no longer with great changes of velocity ( $10-15$ per cent.), but with comparatively small changes of velocity ( $2-4$ per cent). The ball-centres in Proell's governor move in a circle whose centre lies at more than double the height on the other side of the spindle, pretty nearly in $a$. Since the effect of external forces upon a governor is independent of the manner in whch the ball-centres are led in appropriate orbits, it is evident that the working of this modification of Porter's governor is nearly identical with that of a governor in which the doted lines, AB, are actually carried out as rods, and the ball-centres, $\mathrm{B}$, are led in a circle around $\mathrm{A}$.

Fig. 3 shows the hitherto usual construction of pseudo-astatic governors with crossed arms; figs. 2 and 4 the change in the connection of the joints devised by Proell. 
Fig. 3.

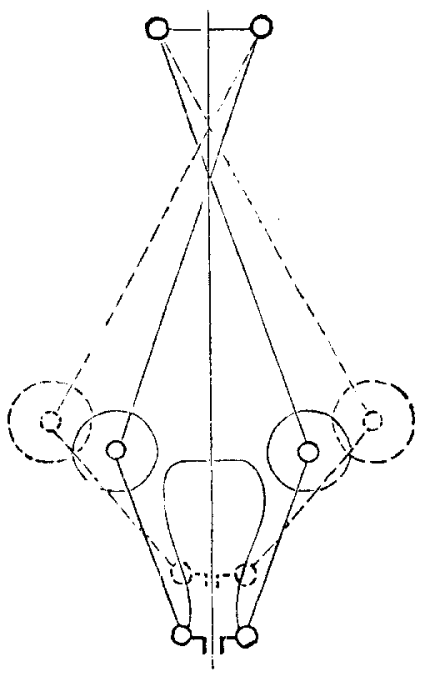

Fig. 4.

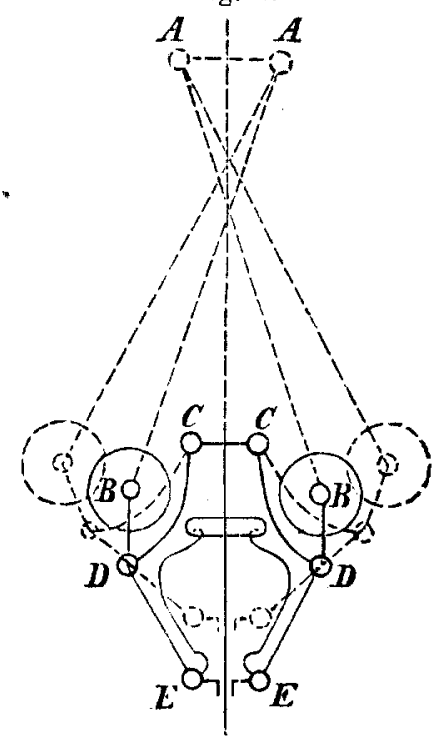

A comparison of the two constructions represented in figs. 3 and 4 shows, in the first place, that the total height of the governor, which, in consequence of the crossed arms, is considerable, is diminished by one-half in Proell's governor (fig. 4). The entire length of the spindle is very small, and, therefore, its journal requires only a box of small height. A prolongation of the spindle beyond the stationary points, C C, will, even with very large governors, not appear as necessary.

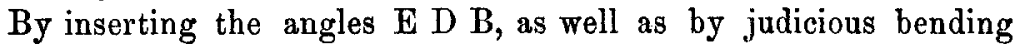
of the upper arms, C B, there is, moreover, a comparatively large space gained for applying a heavy counterbalance, and it becomes possible to fasten large balls on the projecting arms. Upon the weight of the parts of the governor depends its capacity for work. Since now the masses in Proell's governor, in spite of its compendiousness, are very considerable (in the governor marked as III in the subjoined table the balls and the counterbalance alone weigh 54 kg.), it has also a considerable capacity for work, $i$. $e$. it works very energetically. But Proell's governor excels by still another advantage other governors, in consequence of the compendious arrangement of the joint-connections. At a sudden change in the velocity of the governor the balls, in consequence of their inertia, have the tendency of leaving the plane in which the joints are connected. 
The greater this tendency, the stronger is the so-called "edging" and the "wear and tear" at the forks of the suspended arms. Since now the latter in fig. 3 are considerably longer than in fig. 4 the forementioned inconvenience of "edging" and "twisting" will be considerably more diminished in Proell's governor than by the hitherto usual construction of governors with crossed arms, since the respective forces in the former case work through much shorter lever arms. In the latter case the disadvantage to the working of the governor, arising from the "edging" and "twisting" of the joint-connection, may be removed, to be sure, by making the arms stationary at the spindle above the urn, but this produces a greater friction in the moving parts, which again considerably diminishes the sensitiveness of the governor.

The manner of fastening the balls on the projecting arms of the lower connecting links, which is peculiar to Proell's governor, allows an increase or decrease of the distance between the ball-centre and the middle joint by substituting for the little disc lying underneath the ball, a higher or lower one.

In proportion as the distance is increased or diminished the approach to the astatic condition is likewise effected. In the governor, IV, in which the "sleeve," during a change of velocity of 3 per cent. (without regard to resistance), performs a stroke of 75 $\mathrm{m}$. $\mathrm{m}$., the height of the little disc underneath the ball is $12 \mathrm{~m}$. m. If this is replaced by one twice as high, the total increase of velocity is 2 per cent.; if the dise is entirely removed it only amounts to 4 per cent. The approach to the astatic condition is, therefore, doubled with reference to the extremities of the balls. It is possible, therefore, by merely changing the discs under the balls, to ascertain for every given case by experiment the height of the situation of the balls which corresponds to the most favorable working of the governor ; but since at the same time also the number of revolutions of the governor changes within definite limits, a displacement of the balls may be made a means of adjusting the machine for another number of revolutions. At a mean position of the ball, for example, the governor, IV (in the table), makes in the average, without regard to the resistance of friction, 81 revolutions; at the lowest position of the balls $(12 \mathrm{~m} . \mathrm{m}$. lower $) 83$; at the highest $(12 \mathrm{~m}$. m. higher) 79 revolutions.

Finally, it is to be mentioned that very considerable massez may be disposed of in Proell's governor without causing their construction 
to exceed the practicability of execution. Governors, the total height and greatest width of which amounts to only one meter, have a mass of about four cwt., and are, therefore, adapted to a high degree to be used in all those cases in which the regulation of the motor requires a considerable expense of work, as, for example, on water-wheels and turbines for the direct movement of the sluice, and on steam engines where the expansion valves are to be directly moved by the governor. Geometrically all governors resemble each other. On examining the sketch given in fig. 4, which is drawn in three-eighths, three-twentieths, one-fourth, three-fourteenths of the actual size, it will be found to represent the proportions marked as I, II, III, IV, in the subjoined table.

That the number of revolutions of Proell's governor is comparatively a small one must be pronounced as not unessential. For with governors of a great number of revolutions the arrangement for increasing the velocity has often its inconveniences. Likewise the lost motion in the adjusting apparatus, arising from wear and tear, has no great injurious influence upon the manner of working of the governor, because the elevation of the sleeve according to the size, vacillates between 50 and $75 \mathrm{~m} . \mathrm{m}$., i. e. convenient values. The excellent working of Proell's governor has already, practically, been established, and observations and experiments have demonstrated that the value of a change in the motion of from 3-4 per cent. for the total elevation of the sleeve which underlies the constructions is the most convenient approach to the astatic condition.

\section{AMERICAN SOCIETY OF CIVIL ENGINEERS.}

A regular meeting of this Society was held at the rooms in New York, February 19th, 1873.

The Secretary presented the following discussion of a paper " upon the character and position of neutral axes as seen by polarized light," by Louis Nickerson, C. E., of St. Louis, Mo., read before the Society December 18th, last.

CoL. MerriLL.-This paper opens a field for examination which promises the most useful results in a matter of vital interest to engineers:- the laws of strains in materials used for construction. The plan of using glass to find out these laws, brings to mind the practice of physicians in ancient times of determining the laws of the human body, by experiments upon those of the lower animals. 